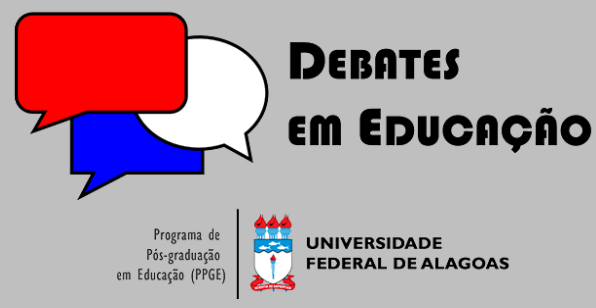

ISSN Eletrônico 2175-6600

Vol. 13 I No. 31 I Jan./Abr. I 2021

Arlete Ramos dos Santos

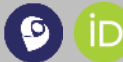

Universidade Estadual do Sudoeste da Bahia

(UESB)

arlerp@hotmail.com

Luciene Rocha Silva

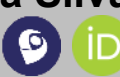

Secretaria de Educação do Estado da Bahia lucienerocha24@gmail.com

\section{AS POLÍTICAS MUNICIPAIS DE EDUCAÇÃO DO/NO CAMPO EM VITÓRIA DA CONQUISTA- BAHIA: UM DIÁLOGO SOBRE A INTERRELAÇÃO COM A POLÍTICA NACIONAL DE EDUCAÇÃO DO CAMPO}

\section{RESUMO}

Este artigo traz o recorte de uma pesquisa de mestrado que objetivou analisar se as ações estruturantes e pedagógicas implementadas no município de Vitória da Conquista sobre a Educação do Campo estavam em consonância com a política nacional de Educação do Campo, que orientam o trabalho pedagógico e curricular nas escolas das áreas rurais. O método utilizado foi o Materialismo Histórico Dialético com enfoque na Pesquisa-Ação, tendo como sujeitos o secretário municipal de educação, coordenadores pedagógicos do núcleo da secretaria e coordenadores e diretores das unidades escolares selecionadas. Os resultados apontam para o distanciamento dos princípios estabelecidos pelas diretrizes, bem como a ausência de uma proposta, que oriente os professores no desenvolvimento da sua prática pedagógica e no fortalecimento da identidade campesina.

Palavras-chave: Educação do campo. Políticas públicas. Educação municipal.

\section{MUNICIPAL POLICIES FOR EDUCATION IN/OF FIELD IN VITÓRIA DA CONQUISTA - BAHIA: A DIALOGUE ON THE INTERRELATIONSHIPS WITH THE NATIONAL POLICY OF FIELD EDUCATION}

\begin{abstract}
This article presents an outline of a research that aimed to analyze if the pedagogical and structuring actions for education in field implemented at Vitória da Conquista were according to national policy of field education, that orient curricular and pedagogical work at schools in rural areas. The methodological approach was the Dialectical and Historical Materialism focused on Action Research, and the subjects were the local Secretary of Education, Education Coordinators directly subordinated to the secretary of education, besides coordinators and principals of selected schools. The results indicate a detachment from the principles stablished by the guidelines as well as the lack of an approach to orient teachers at the development of their pedagogical practice and in order to reinforce the rural identity.
\end{abstract}

Keywords: Education in rural areas. Public policies. Municipal education.

Submetido em: 22/08/2020

Aceito em: 31/01/2021

Publicado em: 26/06/2021

https://doi.org/10.28998/2175-6600.2021v13n31p648-673
Esta obra está licenciada com uma Licença Creative Commons Atribuição-NãoComercial-SemDerivações 4.0 Internacional 


\section{INTRODUÇÃO}

Apresentamos nesse texto um recorte da pesquisa intitulada "A Política Municipal de Educação do Campo em Vitória da Conquista - Bahia, no período de 2010 - 2017", realizada no curso de Mestrado Profissional do Programa de Pós-Graduação em Educação Básica da Universidade Estadual de Santa Cruz (UESC), que teve como objetivo analisar as ações estruturantes, pedagógicas e administrativas da política municipal de Educação do Campo em Vitória da Conquista no período de 2010 a 2017 . A primeira fase da referida pesquisa iniciou-se com a criação do Fórum Municipal de Educação do Campo em Vitória da Conquista - BA (Fomec), em 29/03/2016, na Câmara de Vereadores desta cidade, através de uma Audiência Pública com a participação de movimentos sociais organizados, órgãos públicos municipais e estaduais, entidades e outros colaboradores do Campo e da cidade, a saber: o Movimento dos Sem Terra (MST); o Sindicato do Magistério Municipal Público de Vitória da Conquista (SIMMPNC), além de órgãos públicos municipais, como: Conselho Tutelar Rural (CTR); Conselho Municipal de Educação (CME); Universidade Estadual do Sudoeste da Bahia (UESB); representante da Secretaria Municipal de Educação (SMED); Câmara Municipal de Vereadores (CMV) e representante do Fórum Estadual de Educação do Campo da Bahia (FEEC/BA).

O FOMEC foi criado como produto deste trabalho investigativo que vislumbrou contribuir para o avanço da Educação do Campo no município pesquisado, uma vez que esse organismo se constitui como mais um mecanismo de luta dos movimentos sociais que o integram para assegurar a aplicabilidade das reivindicações dos lutadores e lutadoras do campo, presentes na legislação educacional, ainda não postas em prática pelos gestores públicos. O Fórum é, portanto, um produto da referida pesquisa de mestrado e, conforme o seu Estatuto constituiu-se um "instrumento de mobilização social para fiscalizar, monitorar, inferir e refletir sobre a Educação do Campo. Este foi o propósito e a finalidade da sua criação" (FOMEC, 2016).

Nessa perspectiva, a criação desse organismo político teve um significado duplamente especial. Primeiro, por ser um instrumento de luta e mobilização social para os defensores da Educação do Campo, aqueles professores e militantes sociais que compreendem a importância da luta por uma educação básica no campo com qualidade. Segundo, porque esse agrupamento também se constituiu como sujeito integrante na pesquisa, colaborando na coleta de dados e de informações por meio de entrevistas e 
catalogação de documentos oficiais, aplicação de questionários, bem como nas reflexões dos resultados, fruto das análises documentais, conforme orienta a pesquisa-ação.

A palavra "Fórum" se define como um espaço de unificação entre a sociedade civil e o Estado brasileiro para reivindicar direitos da comunidade, fruto de deliberações realizadas em conferências educacionais, encontros em âmbito nacional, estadual ou mesmo local. É, portanto, um órgão político composto por vários setores organizados da sociedade civil e do Estado. Existem vários fóruns de educação constituídos no Brasil e no mundo, devido a sua capacidade mobilizatória em reunir entidades de diferentes organismos sociais que, por meio de uma pauta política, vêm demonstrando os problemas existentes e a necessidade da criação de uma força política interna para o coletivo. No caso da Educação do Campo, temos os fóruns nacional, estaduais e municipais (FONEC, 2010).

O texto está dividido em cinco partes, a saber: 1) esta breve introdução que fala do propósito da pesquisa; 2) contextualização da Educação do Campo, com destaque para as políticas educacionais implementadas e a correlação de forças entre o agronegócio e o campesinato; 3) discussão sobre os aspectos metodológicos da pesquisa apresentando os diversos momentos e ações do FOMEC; 4) apresentação dos resultados da pesquisa com destaque para a relação entre o instituído no município, correlacionando-o com a política nacional de Educação do Campo; e 5) algumas considerações a partir dos achados da pesquisa.

\section{A LUTA PELA EDUCAÇÃo dO CAMPO E AS POLíticas PÚBLICAS EDUCACIONAIS}

A Educação do Campo no Brasil, em seu processo histórico, é tratada pelas legislações constitucionais anteriores à década de 1980, de forma excludente e silenciosa, mas, na década de 1990, as lutas dos movimentos sociais por políticas públicas e melhores condições de vida no campo trazem algumas conquistas, as quais serão descritas mais à frente. A partir dessa década, verificam-se contextos diversos de articulações e mobilizações em favor de uma educação humanística e emancipatória, visando ao fortalecimento da identidade camponesa e a garantia de melhores condições de vida para os agricultores.

A Lei de Diretrizes e Bases da Educação Nacional (LDBEN) nº 9.394/96, quando define o termo "Educação", afirma em seu Art. $1^{\circ}$ que "os indivíduos podem ser educados 
e se tornar cidadãos na convivência familiar, na escola, nas organizações sociais, por meio da sua cultura, do seu trabalho" (BRASIL, 1996). Reconhece, pois, que a escola e os espaços extra escolares são também lugares de aprendizagem para o exercício da cidadania, portando, espaços de aquisição de conhecimentos, os quais são considerados pela referida legislação educacional como espaços educativos.

O dispositivo legal alusivo à Educação do Campo no artigo 28 da LDBEN (9.394/96), ainda que a denomine Educação para as áreas rurais, legitima uma modalidade específica de educação para os povos campesinos e intrinsecamente reconhece as diferenças entre a vida do campo e a vida da cidade, que necessariamente precisam ser respeitadas e trazidas para o ambiente da escola. Posto que o campo se constitua um espaço heterogêneo que se destaca pela sua diversidade econômica, em função do engajamento das famílias em atividades agrícolas e não agrícolas, pela presença de fecundos movimentos sociais, pela grandeza da sua multiculturalidade, as demandas existentes em prol de uma educação básica e a dinâmica que se estabelece a partir da convivência com uma cultura letrada ${ }^{1}$ exigem uma especial atenção no campo das políticas públicas (SOARES, 2001).

Sendo assim, destacamos dois paradigmas para se pensar o processo educativo dos povos campesinos, quais sejam: o paradigma da Educação do Campo e o paradigma da Educação Rural. Paradigmas são compreendidos como "as realizações científicas universalmente reconhecidas que, durante algum tempo, fornecem problemas e soluções modelares para uma comunidade de praticantes de uma ciência". (KUHN, 2006, p. 13). No estudo, o paradigma da Educação do Campo tem natureza emancipatória e humanística; define-se por incorporar não apenas os processos de escolarização dos sujeitos sociais do campo, mas, sobretudo, por preocupar-se com a formação humana dos camponeses (RIBEIRO, 2013). Uma educação que se volta para o trabalho, a cultura, o jeito de ser, viver e de conviver, as relações com o outro, e ainda aquela que procura corroborar a identidade do homem e da mulher do campo, voltada não só para o mercado de trabalho, mas para a vida em sociedade. Uma educação que contempla os saberes, as vivências e experiências dos sujeitos coletivos que habitam os espaços de identidade cultural (SANTOS; NUNES, 2020).

Todavia, o paradigma da Educação Rural traz sentidos diferentes do que se compreende por Educação do/no campo, pois sustenta o modelo educacional para este

\footnotetext{
1 SOARES, Édila de Araújo. Relatora do Parecer 036/2001, do Conselho Nacional de Educação através da Comissão de Educação Básica do qual foram extraídas as informações contidas no corpo do texto.
} 
espaço numa perspectiva urbanocêntrica, de estrutura precária, com sujeitos desprovidos de conhecimentos, portanto, tendo como base esse discurso, justifica a subalternização do camponês pelos citadinos que se consideram "civilizados" (SANTOS, 2016). Este paradigma está pautado no projeto histórico de sociedade do patronato rural por meio dos órgãos públicos estatais, e visa preparar o cidadão para atender ao mercado com sua força de trabalho, técnico ou especializado, Já o primeiro pensa a Educação do/no Campo como aquela que é pensada pelos camponeses e movimentos sociais como sujeitos políticos coletivos, com base em sua realidade social, proveniente das suas lutas sociais, e visa preparar os educandos para a vida em sociedade numa perspectiva de educação mais humanística. A nomenclatura indica que o povo tem direito a uma educação pensada desde o seu lugar de convívio e com a sua participação, vinculada à sua cultura e às suas necessidades humanas e sociais. Portanto, é uma educação implícita no contexto da formação humana com princípios emancipatórios (CALDART, 2002).

Até a década de 1990, a educação para os povos do campo na legislação nacional ainda era conhecida apenas como Educação Rural e atendia aos interesses do patronado rural por intermédio do Estado, que procurava minimizar o conhecimento universal para essa camada social. Segundo Ribeiro (2013), essa denominação ainda é muito usada pelos trabalhadores rurais, sindicatos e até mesmo por organizações sociais, principalmente em algumas regiões do país como no Rio Grande do Sul, demarcando a realidade da cultura e do trabalho, mesmo estando envolvidos na luta pela Educação do Campo.

Portanto, destacamos o ápice da Educação do Campo na agenda política e na política educacional a partir da LDBEN $n^{\circ}$. 9.394/96, quando afirma em seus artigos 23 , 26 e 28 a possível adequação do currículo e de metodologias apropriadas ao meio rural, bem como a flexibilização da organização do trabalho pedagógico, além da possibilidade de adequação do calendário escolar às condições climáticas de cada região. Com base nesse contexto, as políticas públicas educacionais vistas como direito, voltadas para a Educação do Campo, começam a tomar fôlego e se alargar no cenário nacional, a partir da década de 1990 (SILVA, 2017).

As primeiras discussões sobre o tema Educação do Campo emergiram no I Encontro Nacional de Educadores da Reforma Agrária (I ENERA), realizado em Brasília em 1997, o qual gerou tais reflexões sobre essa realidade de ensino e, posteriormente, em 1998, 2004, 2015, com a realização das respectivas Conferências para Educação Básica no Campo, além de outros encontros com a mesma finalidade, envolvendo a 
participação de intelectuais acadêmicos, organismos internacionais, da sociedade civil e órgãos do governo Federal como: Ministério da Educação (MEC); a Organização das Nações Unidas para a Educação, a Ciência e a Cultura (UNESCO); Universidades Federais e Estaduais, além de outros. Posteriormente, as mobilizações sociais se intensificaram e incorporaram a luta por Educação do Campo, por intermédio das ações e reinvindicações dos Movimentos Sociais e Sindicais do Campo, em harmonia com outros movimentos urbanos (SANTOS, 2013).

Devido ao seu contexto, a natureza da educação para os povos do campo volta-se, em sentido amplo, para a formação humana que constrói referências culturais e políticas para a intervenção de pessoas e dos sujeitos sociais na realidade, visando a uma sociedade mais plena e digna. Nesse sentido, o campo traduz um lugar onde as pessoas vivem para trabalhar e estudar com dignidade, pois ocupam um território que possui determinadas peculiaridades que se diferenciam do espaço urbano e são possuidores de uma identidade cultural própria, específica (FERNANDES, 2002 apud KOLLING; CERIOLLI; CALDART. 2002).

Fernandes e Molina (2004) percebem o "Campo" da Educação do Campo, em sua etimologia, a partir do conceito de "território" como o espaço de excelência, "campo de ação e poder": "O território é um triunfo dos povos do campo e da floresta. [...] Ter seu território implica em um modo de pensar a realidade [...]". (FERNANDES; MOLINA, 2004, p. 53 e 60). O território, portanto, é concebido pelos autores por lugar historicamente transformado pelos homens em suas relações sociais. São espaços simbólicos permeados pela diversidade cultural, étnico-racial, pela multiplicidade de gerações e recriações de saberes, de conhecimentos que são organizados com lógicas diferentes, de lutas e mobilizações sociais, de estratégias de sustentabilidade e nos remete a uma compreensão de desenvolvimento humano associado ao fortalecimento e ampliação de capital social, a partir de vínculos sociais, culturais e de relações de pertencimento a um determinado lugar, para a construção e fortalecimento de uma identidade própria e de um território sustentável (SILVA, 2017). O Brasil é um país que "foi consagrado pela história um padrão agrário de acumulação de terra, que criou os latifúndios no século $X X e$ favoreceu para que os governantes da época preterissem a formação escolar das comunidades de origem rural, usando como subterfúgio o argumento do paradigma agroexportador vigente naquele período" (SILVA; MORET 2020, p.3).

Essa concepção de educação do meio rural, conhecida como "Educação do Campo", possui um sentido mais amplo e complexo e deve abranger não só o processo 
de escolarização, mas a formação do homem e da mulher do campo para a vida, desenvolvendo nos sujeitos sociais capacidades para um maior poder de intervenção social. Esta educação também está presente na visão de Caldart, afirmando que a educação do campo deve:

[...] ter vinculo de origem com as lutas sociais. Pensar a educação dos sujeitos do campo desde o vínculo com a luta pelos direitos das mulheres camponesas, com a luta pela reforma agrária e por um projeto camponês de desenvolvimento do campo, com a luta por democratização do acesso à água. A Educação do Campo não precisa e nem deve ser um projeto de educação apenas dos camponeses nem apenas de quem participa das lutas sociais; mas este vinculo lhe confere a traço de identidade importante que não pode ser perdido. [...] (CALDART, 2004a, p.34).

A história tem revelado que a Educação Rural considera apenas a formação escolar; é fundamentada nos pressupostos capitalistas do agronegócio e do Estado, ao passo que a Educação do Campo valoriza as práticas educativas, pensadas e efetivadas pelos próprios povos do campo. Portanto, esta última trata de uma concepção de educação voltada à indagação do campo como espaço brasileiro, da cultura, identidade e relações de trabalho que marcam a vida dos povos que vivem no campo. Uma educação voltada para a emancipação social do homem visando a sua humanização (SOUZA, 2002; SANTOS, NUNES, 2020).

Entendemos as políticas públicas, com base em Machado e Vendramini (2013), como forma de regulação por intermédio do Estado das relações entre desiguais, conforme características da sociedade capitalista. Para Caldart (2004), as políticas públicas são desenvolvidas pelo Estado nos âmbitos Federal, Estadual e Municipal para atender a demandas que provém de determinados setores da sociedade civil. Portanto, as políticas direcionadas a essa modalidade de ensino são fruto de intensas lutas cotidianas dos movimentos sociais, articulados nacionalmente com o Movimento de Educação do Campo. Esses sujeitos sociais, através de suas práticas mobilizatórias e educativas, têm sido capazes de questionar e apresentar novas alternativas ao projeto do Estado voltado para o desenvolvimento no meio rural, em específico os projetos educativos realizados nas escolas do campo. Os reflexos dessas ações políticas resultaram em avanços e conquistas em direção às políticas públicas para a Educação Básica do Campo. (MOLINA; FREITAS, 2011).

O êxito destas mobilizações e reivindicações articuladas pelos Movimentos Sociais, já sinalizadas em décadas anteriores, foi obtido em final dos anos de 1980, com a 
promulgação da Constituição Federal em 1988, quando o Estado consolidou o compromisso com a sociedade em promover a Educação enquanto um direito para todos os cidadãos brasileiros, sem nenhum tipo de distinção, bem como a sua adequação às especificidades culturais e regionais. Em 1998, foi criada a Articulação Nacional de Educação do Campo, entidade supra-organizacional que passou a gerir as ações pela escolarização dos povos do campo. Este sujeito coletivo conseguiu organizar duas importantes Conferências Nacionais para Educação do Campo, sendo uma em 1998 e outra em 2004 - ambas realizadas em Luziânia, estado de Goiás-; e foi atuante na construção das Diretrizes Operacionais para a Educação Básica do Campo em 2002 e do Grupo Permanente de Trabalho do Campo (GPT) em 2003, aprovado pelo Conselho Nacional de Educação (CNE). Esses foram alguns dos resultados das lutas sociais iniciadas nas décadas de 1980/1990 e os avanços conquistados em prol de uma educação básica para os povos camponeses.

A política silenciada sobre os povos do campo foi quebrada com as lutas dos camponeses organizados e, consequentemente, com o surgimento da "Articulação por uma Educação Básica do Campo", que devolveu a esses povos a esperança de se incluírem na pauta do desenvolvimento socioeconômico do país. A Educação do Campo, a partir de então, nasce com um novo olhar de uma educação da classe trabalhadora que vive no campo, agora com uma visão mais crítica e consistente sobre o papel da escola e o ato de educar, vistos como um direito social, emancipatório e humanístico.

\section{ASPECTOS METODOLÓGICOS DA PESQUISA}

O caminho metodológico para o desenvolvimento da pesquisa deu-se por meio do Materialismo Histórico Dialético (MHD), com a utilização da pesquisa-ação, cujos dados foram coletados mediante a aplicação de questionários, realização de entrevistas e análise de documentos oficiais. "A dialética é o pensamento crítico que se propõe a compreender a 'coisa em si' e sistematicamente se pergunta como é possível chegar à compreensão da realidade". (KOSIK, 1976, p. 19).

A prática da pesquisa-ação neste estudo foi realizada juntamente com a participação dos membros integrantes do FOMEC, criado pela pesquisadora, com a participação dos movimentos sociais do campo para acompanhar, monitorar e inferir sobre a Educação do Campo no município de Vitória da Conquista. Esses sujeitos foram inseridos como colaboradores no processo da coleta de dados, no acompanhamento das 
entrevistas, aplicação de questionários, participando das reuniões e acompanhamento do processo de análise, intervindo sobre as informações coletadas, as quais eram previamente organizadas em tabelas ou quadros de análises conforme as categorias evidenciadas para serem refletidas pelo coletivo do Fórum. "[...] a pesquisa-ação traz uma visão emancipatória e crítica da realidade e contribui para a reflexão sistemática sobre a prática social e educacional com vistas a sua melhoria e mudanças, tanto pessoal como social". (ESTEBAN, 201015 ), Thiollent (2011) também define essa abordagem como a que mais se aproxima do materialismo histórico pelo envolvimento integral e espontâneo de um grupo cujos membros, ao mesmo tempo em que são sujeitos de ação, são também objetos de observação num determinado processo de investigação, proporcionando-lhes conhecimento e uma nova consciência da realidade pesquisada.

O envolvimento dos sujeitos na pesquisa, conforme preconiza a pesquisa-ação, aconteceu em diversos momentos, a saber.

1) Apresentação do projeto - nesse momento, explicamos aos presentes sobre a pesquisa, bem como a importância da participação de todos no processo como sujeitos, interlocutores e colaboradores, dada a possibilidade de ampliação de conhecimento;

2) Momento da formação - houve estudos sobre a Educação do Campo e as políticas públicas. Contamos com o envolvimento de todos os representantes do FOMEC, o que se constituiu também um momento importante para o fortalecimento da identidade social do Fórum. Os estudos realizados, principalmente sobre as Diretrizes Operacionais para a Educação do Campo (Res. CNE/CEB nº 02/2002), demonstraram que o município investigado não cumpria a legislação sobre a modalidade de ensino pesquisada. Nesse sentido, os integrantes do FOMEC resolveram criar uma proposta de resolução municipal da Educação do Campo para apresentar ao Conselho Municipal de Educação (CME).

3) Momento da criação da proposta de resolução de Educação do Campo pelo FOMEC.

Foi um processo de ação-reflexão-ação, portanto dialógico, uma vez que a pesquisadora colheu os dados da pesquisa juntamente com o Fórum, e reelaborou coletivamente, observando as questões teóricas, bem como, a legislação da educação do campo. Só então, depois da coleta de dados e dos estudos, foi elaborada a proposta de Resolução Municipal de Educação, sendo necessária a realização de três reuniões convocadas para análise e avaliação das propostas elaboradas, pelos integrantes. A primeira, na qual aconteceu a elaboração da primeira versão da proposta de Resolução; na segunda, foi elaborada uma segunda versão com as alterações propostas pelo Fórum, na qual foram feitas novas correções e aprovada como documento final; e na terceira versão, depois de corrigidas as alterações fora apresentada aos gestores da Secretaria Municipal de Educação (SILVA, 2017, p. 137). 
Depois da fase de construção da proposta de resolução, aconteceu a próxima etapa.

4) Apresentação da proposta de resolução para o $\mathrm{CME} \mathrm{-} \mathrm{foi} \mathrm{realizada} \mathrm{uma} \mathrm{reunião}$ para apresentação e discussão do documento no $\mathrm{CME}$, a qual contou com a presença dos coordenadores do Núcleo Pedagógico; a Coordenação geral do Núcleo, do Vicepresidente do Conselho Municipal de Educação; Diretora das Escolas Nucleadas da zona rural; integrantes do FOMEC representados pelo MST, Grupo de Estudos e Pesquisas em Educação do Campo (GEPEC/UESB), a pesquisadora e a professora da Universidade Estadual de Santa Cruz (UESC) Arlete Ramos dos Santos, que orientou a pesquisa de mestrado da qual este artigo se origina.

\footnotetext{
Este foi um momento importante para os membros do Fórum e a pesquisadora, vez que todo o trabalho de coleta de dados, análises e elaboração se resumia nesta Resolução. Ali começava os primeiros passos da intervenção e sua contribuição para amenizar as contradições existentes na prática educacional para a população do meio rural (SILVA, 2017, p. 139).
}

Para obtenção de resultados dessa pesquisa de campo foram aplicados 33 questionários e realizadas cinco entrevistas tendo como sujeitos: o Secretário Municipal de Educação, a coordenadora geral da Secretaria Municipal de Educação (SMED); uma coordenadora pedagógica da SMED, que atua no Núcleo Pedagógico dando assistência aos professores dos anos iniciais do Ensino fundamental e das classes Multisseriadas das escolas do campo; a gestora das Escolas Nucleadas Rurais e a gestora do Círculo Escolar Integrado de Cabeceira, além de professores efetivos que trabalham nas respectivas escolas.

Os questionários foram aplicados aos professores que trabalhavam em escolas do campo à época, e foram distribuídos em reuniões de planejamento, previamente organizadas pela escola ou pela Secretaria de Educação, com autorização dos gestores. Os documentos coletados para alcançar o objetivo dessa pesquisa no município foram relatórios anuais de trabalho, atas, decretos, resolução, portarias, Plano Municipal de Educação, Regimento Unificado das Escolas da rede de ensino, decretos de eleições para diretores da rede municipal, relatórios de transporte escolar, dados estatísticos de desempenho escolar da zona rural, relatório das escolas nucleadas rurais, relatório anual dos anos iniciais do Ensino Fundamental, relatórios do Núcleo Pedagógico, Calendários 
As Políticas Municipais de Educação do/no campo em Vitória Da Conquista- Bahia: um diálogo sobre a interrelação com a

Escolares, além de outros considerados importantes relacionados ao período de 2010 a 2017.

Por se tratar de uma pesquisa-ação, o FOMEC, como sujeito da pesquisa, teve um duplo significado. Primeiro, por simbolizar um instrumento de luta e mobilização social em defesa da Educação do Campo, envolvendo professores e militantes sociais que são comprometidos com a luta por uma maior qualidade da educação básica no campo. Segundo, porque esse grupo político de luta tornou-se sujeito integrante da pesquisa, colaborando na coleta de dados e de informações por meio de entrevistas e catalogação de documentos oficiais, aplicação de questionários, além da contribuir com importantes reflexões nos resultados, advindos das análises documentais, conforme incentiva a pesquisa-ação. Desde o primeiro momento da sua instituição até o momento final da pesquisa, este fórum colaborou como um sujeito de grande importância e atualmente, em 2020, continua realizando a luta pela implementação de uma educação que respeita o homem do campo no município de Vitória da Conquista.

Os dados coletados demonstraram contradições observadas na implementação da política municipal de Educação do Campo, a exemplo do alto número de fechamento das escolas; a falta de prioridade para o atendimento à Educação Infantil no campo; o distanciamento da legislação municipal para com as Diretrizes Operacionais da Educação do Campo que orientam as escolas campesinas; currículo distante da realidade rural e formação continuada dos professores inadequada para o fortalecimento da identidade camponesa. Tais elementos são resultantes das análises de entrevistas, questionários e documentos oficiais e se apresentam como resultados desta pesquisa a seguir.

\section{A EDUCAÇÃO DO CAMPO NO MUNICÍPIO DE VITÓRIA DA CONQUISTA - BAHIA - ACHADOS DA PESQUISA}

Vitória da Conquista, uma cidade bastante hospitaleira, está localizada no planalto da Conquista, especificamente na Serra do Periperi, a aproximadamente $900 \mathrm{~m}$ de altitude, na regional do Sudoeste da Bahia/Brasil, considerada como o terceiro município mais populoso que se aproxima de 398 mil habitantes, em comparação às demais cidades que integram ao estado (IBGE, 2016). Uma urbe que acolhe estudantes de várias localidades e de outros estados, considerado um polo educacional devido às instalações de universidades públicas e privadas e Instituto Federal de Educação, ofertando uma variedade de cursos de nível superior à população estudantil. 
A Educação do Campo no município de Vitória da Conquista não se diferencia muito das referências da educação no âmbito nacional. O que se verifica é que esta modalidade de ensino não tem sido implementada ao longo dos anos, mesmo com o incentivo das políticas públicas conquistadas pelos Movimentos Sociais a partir dos anos 1990, principalmente devido à política de resistência dos gestores municipais em aderir às orientações oferecidas pelas Diretrizes Operacionais para a Educação Básica do campo.

A Rede Municipal de Educação em Vitória da Conquista se diferencia das outras redes de ensino devido à sua extensão territorial, sendo em área geográfica a primeira cidade do estado da Bahia em área rural e a terceira do país, com aproximadamente $2.663 \mathrm{~km}$ em extensão territorial, o que caracteriza uma posição de destaque em relação a outras grandes cidades baianas, como Feira de Santana, Itabuna, Ilhéus e Jequié. Conforme divulgação no site da Prefeitura Municipal de Vitória da Conquista (PMVC), a Secretaria Municipal de Educação (SMED), até 2015, era composta por 202 unidades escolares que atendiam dois níveis de ensino, o Ensino Fundamental e a Educação Infantil.

Algumas dessas informações aparecem desencontradas entre o que está publicado no site da $\mathrm{PMVC}^{2}$ e as informações contidas nos documentos oficiais apresentadas pela SMED. Contudo, os dados pesquisados em 2015 na SMED demonstram que este setor público era responsável por 137 escolas assentadas no meio rural, que contrastam com as 41 unidades escolares e 21 creches instaladas na zona urbana do município, totalizando 199 unidades de ensino na rede municipal. Do conjunto das creches apenas uma existente no meio rural. Para 2016, o número de escolas foi reduzido em sua totalidade para 196 instituições educativas, passando para 134 o número de escolas do campo, 41 escolas urbanas e 21 creches. Para 2017, com a política de fechamento das escolas com classes multisseriadas, este número caiu para 187 instituições de ensino em seu total. Dessas unidades de ensino, apenas 116 escolas localizam-se no campo, enquanto 45 escolas e 25 creches são urbanas, sendo que, do número de creches apresentado, apenas uma permanece funcionando no meio rural. Enquanto na cidade constata-se uma oferta de crescimento de escolas como de creches para atender à população urbana, no meio rural verifica-se a redução de escolas com a política do fechamento ou de nucleação, o que configura uma inversão de prioridade na educação municipal para com a educação infantil e fundamental no campo (SMED, 2016).

2 Disponível em: www.pmvc.org.ba 
As Políticas Municipais de Educação do/no campo em Vitória Da Conquista- Bahia: um diálogo sobre a interrelação com a

Atualmente, a rede municipal conta em sua totalidade com apenas 178 unidades escolares, sendo 94 escolas localizadas no meio rural e 52 escolas situadas no espaço urbano. O município conta ainda com 23 creches municipais e 8 conveniadas, totalizando 31 espaços reservados para o trabalho com a educação infantil. Destas, apenas uma creche atende à população do meio rural (SMED, 2020).

O organograma da Secretaria Municipal de Educação em 2017 estava composto pela estrutura administrativa que controla e orienta o sistema e a política educacional no município e, na distribuição de cargos, trazia as seguintes funções: Assessor de Gabinete; coordenação Administrativa Escolar; Coordenação Administrativa Financeira; Coordenador do Núcleo Pedagógico; Coordenador do Núcleo Infantil; Coordenador de Alimentação Escolar; Coordenador de Transporte Escolar; Núcleo de Educação Especial; Núcleo do Ensino Fundamental e Núcleo de Tecnologia e Informações, conforme demonstra a Figura 1:

Figura 1: Organograma da Secretaria Municipal de Educação (PMVC, 2017)

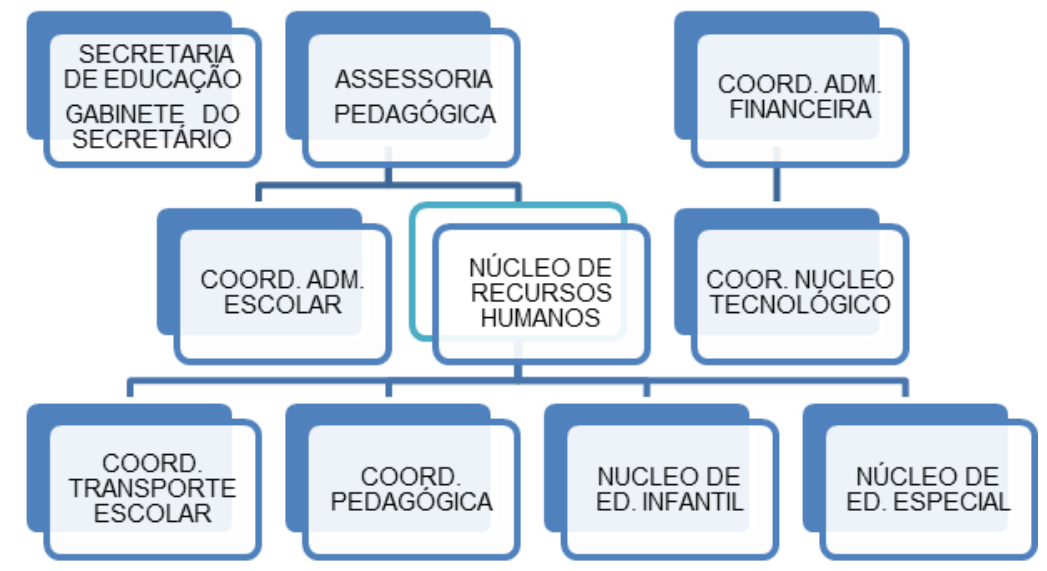

(Fonte: PMVC, 2017).

Observa-se que este organograma não leva em consideração a extensão rural, que é predominante no município. No conjunto das atribuições não se observa, contudo, na sua estrutura organizativa, uma coordenação administrativa e pedagógica específica para o meio rural, passando a ideia da indiferença política por parte do poder público a essa realidade social, bem como às Diretrizes Operacionais que orientam a educação nas escolas do campo do país, no que se refere ao respeito às especificidades educacionais que vinculam o direito social dos cidadãos camponeses ao fortalecimento da cultura, da identidade, da formação humana, como procedimentos estratégicos para o desenvolvimento social nesse espaço de convivência social. Também nos conduz a um 
As Políticas Municipais de Educação do/no campo em Vitória Da Conquista- Bahia: um diálogo sobre a interrelação com a

pensamento crítico sobre o não reconhecimento dos direitos conquistados pelo homem do campo, a partir das suas lutas sociais após a década de 1990.

A Secretaria Municipal de Educação de Vitória da Conquista contava em 2017 com uma quantidade aproximada de 3.400 servidores para atender à rede de ensino. Dentre os profissionais, 1.785 são professores efetivos e contratados que absorvem um universo de aproximadamente 43.000 alunos. Destes, cerca de 13.400 educandos estão matriculados em Escolas do Campo, o que representa um percentual acima de $30 \%$ do total de alunos matriculados em 2015. As escolas da rede, em seu conjunto, estão organizadas em Unidades Independentes, Círculos e Núcleos instalados nos diferentes espaços urbanos e localidades rurais. São responsáveis pela Educação Infantil; Ensino Fundamental Inicial e Final, distribuídos nos três turnos de funcionamento (matutino, vespertino e noturno), com inserção de classes de Educação de Jovens e Adultos no noturno. Em comparação com as matrículas do ano letivo de 2020, esses números sofrem alterações significativas. Atualmente, a rede municipal de ensino atende, em sua totalidade, a 40.331 alunos distribuídos nos diferentes níveis do Ensino Fundamental (inicial e final) e da Educação Infantil. Destes, apenas 10.014 encontram-se matriculados nas escolas rurais do município, representando um percentual de $24,8 \%$ em comparação com as matrículas de alunos nas escolas urbanas, o que sinaliza uma crescente redução da população estudantil do campo (SMED, 2020).

Em 2020, nem todas as escolas do campo no município pesquisado possuem coordenadores pedagógicos, sendo mais assistidas por esses profissionais aquelas integradas aos círculos escolares que são compostos, geralmente, pelo mínimo de três e máximo de oito escolas de pequeno porte, próximas umas das outras, compostas de duas salas de aula, localizadas na zona rural, e as situadas na zona urbana. As Escolas pertencentes aos Círculos Intermediários ou Escolas Nucleadas rurais que, em sua maioria, estão organizadas por classes bisseriadas (aquelas organizadas por duas séries) e multisseriadas (compostas por classes do $1^{\circ}$ ao $5^{\circ}$ ano), também não são atendidas por coordenadores pedagógicos escolares, que visitam esporadicamente as escolas por falta do transporte, deixando lacunas no acompanhamento escolar.

Já em 2016, ano da coleta de dados desta pesquisa, as classes multisseriadas geralmente possuíam de um a dois coordenadores pedagógicos escolares, centrados na Secretaria de Educação, para atender ao universo das escolas que apresentam essa forma de organização escolar no município. Apenas um coordenador pedagógico realizava o trabalho de acompanhamento e supervisão das classes multisseriadas para 
As Políticas Municipais de Educação do/no campo em Vitória Da Conquista- Bahia: um diálogo sobre a interrelação com a

assessorar um total de 46 professores, distribuídos entre as 42 escolas que integravam o Círculo das Escolas Nucleadas, em sua maioria, formadas por este tipo de classes (SILVA, 2017).

O currículo tratado no ambiente das Escolas do Campo neste município vem se distanciando das experiências, do conhecimento e da identidade dos camponeses. A cultura e o currículo são condições lógicas para o ensino nas escolas do campo. Defende Sacristán (2000) que a realidade cultural de um país, principalmente aquela voltada para os mais pobres, cuja principal oportunidade de adquirir conhecimento é a escolarização obrigatória, ainda está muito relacionada com a significação dos conteúdos e dos usos dos currículos escolares. Reafirma ainda que "a cultura geral de um povo depende da cultura que a escola torna possível enquanto se está nela, assim como dos condicionamentos positivos e negativos que se desprendem das mesmas [...]" (SACRISTÁN, 2000, p. 30).

O currículo nas escolas do campo, portanto, deve preparar os seus educandos para a vida em sociedade, numa perspectiva emancipatória, e não apenas para atender as exigências do capital, implícitas nos planos de curso baseados em conteúdos que priorizam conhecimentos sobre o mercado de trabalho com suas inovações tecnológicas, assegurados pelo poder público, através da sua legislação nacional que orienta o currículo nos diferentes sistemas de ensino dos municípios e estados federados (SOCORRO; SANTOS; NUNES, 2017). Como dito anteriormente, o artigo 26 da LDB 9.394/96 estabelece essa diferenciação de currículo quando da elaboração das propostas pedagógicas. Este deve respeitar as particularidades específicas de cada região do país. O novo paradigma (da Educação do Campo) ganha fôlego e se fortalece enquanto princípio norteador estabelecido pelo Decreto 7.352/2010, em seu Artigo $2^{\circ}$, Inciso IV, quando assegura:

[...] "a valorização da identidade da escola do campo por meio de projetos pedagógicos com conteúdos curriculares e metodologias adequadas às reais necessidades dos alunos do campo, bem como flexibilidade na organização escolar, incluindo adequação do calendário escolar às fases do ciclo agrícola e às condições climáticas" (BRASIL, 2010, p. 2).

Conforme Silva (2017), a SMED já tentou implementar uma proposta pedagógica para a educação do meio rural no município, coerente com as exigências curriculares para os espaços campesinos cujo processo teve início em 2005, quando fora apresentada e discutida com os professores que atuam nas escolas do campo, procurando atender ao artigo 28 da lei 9394/96 que dispõe sobre a Educação do Campo, além das Diretrizes 
Operacionais para a Educação Básica nas Escolas do Campo publicadas em 2002. A referida Proposta foi aprovada pelo Conselho Municipal de Educação em 2007, por meio da Resolução CME n 10/2007, e colocada parcialmente em prática até 2008, conforme o que estabelecia a Resolução, contudo a sua execução não foi exitosa devido a algumas resistências dos professores do campo por falta de conhecimento sobre as Diretrizes Operacionais. A partir do ano de 2009, com a chegada de um novo secretário de educação no município, a proposta foi deixada de lado, dando prosseguimento a uma nova concepção de educação para os povos do campo a partir de 2010, investindo numa proposta de currículo único (urbanocêntrico) para o meio rural e urbano.

De acordo com Souza e Marcoccia (2011), as relações entre escola e comunidade se dão por meio dos projetos pedagógicos realizados em datas comemorativas, ou pelas reuniões de pais e mestres para tratar apenas ou exclusivamente da vida escolar do aluno. Os saberes, as formas de relações dessas famílias, a sua cultura, estão sempre à revelia, sem importância para um trabalho curricular sistematizado na sala de aula, ficando sempre para um segundo plano. Na maioria das escolas a cultura do homem do campo é vista como folclórica, lembrada apenas pelas comemorações da escola em datas considerada especiais no calendário letivo, como os festejos juninos, o reisado, apresentado na comemoração do folclore ou nas festas natalinas, as atividades comparativas representando a vida no campo e a vida na cidade em forma de apresentação teatral. Importa apenas internalizar no imaginário desses sujeitos a necessidade de estudar para servir de assalariados no mundo do trabalho urbano. (SILVA, 2017).

A formação continuada do professor que atua na educação do meio rural do município também deveria ser diferenciada, orientando-o com informações e conhecimentos que subsidiassem a sua relação com os alunos e a comunidade e o ajudassem a compreender melhor as situações vividas pelo o homem do campo. Também se constata uma contradição na práxis pedagógica dos gestores educacionais: não apenas desrespeitam os pressupostos legais previstos nas diretrizes operacionais como os princípios elencados no Decreto 7.352/2010, que dispõe da política de Educação do Campo, anunciando em seu Inciso III: "desenvolvimento de políticas de formação de profissionais da educação para o atendimento as especificidades das escolas do campo, considerando-se as condições concretas de produção e reprodução da vida social no campo;" (BRASIL, 2010, p. 2). 
As informações obtidas denotam que o trabalho desenvolvido pelos gestores da SMED ainda não tem apresentado as condições objetivas necessárias para conduzir os alunos a uma educação emancipatória, humanizada e cidadã, ao trabalho específico de cada realidade social, que eleve a auto-estima, a criatividade e a capacidade crítica dos aprendentes. Seu modelo de educar revela uma intenção voltada apenas ao processo de codificação e decodificação, visando assegurar as competências básicas para os filhos da classe trabalhadora, como está expresso no documento oficial para apresentar o princípio básico que direciona a concepção de educação do município, que é a de assegurar o aluno na escola lendo, escrevendo e operacionalizando. Os atos de ler, escrever e contar são os elementos básicos que o Estado propõe para a classe trabalhadora, tanto urbana como a camponesa, para viver em sociedade.

A LDB $n^{\circ}$ 9.394/96 é flexível no que se refere à organização do trabalho pedagógico. Nesse sentido, as classes multisseriadas estão presentes em um grande número de unidades escolares e um dos principais motivos tem sido a baixa densidade demográfica no campo, além da mobilidade dos seus sujeitos sociais em busca de trabalho e sobrevivência, pressionados pelo agronegócio na região, com sua política de expropriação de terras nas comunidades rurais consideradas com grande teor de produtividade.

As classes multisseriadas são asseguradas pela legislação educacional quando trata na LDB atual, nos artigos 23,26 e 28, sobre a organização das classes e o respeito às especificidades culturais no meio rural. Entende-se por classe multisseriada aquela formada por alunos que estudam juntos numa classe com mais de uma série no mesmo espaço educativo. Segundo relatório das Escolas Nucleadas Rurais (2015), a rede municipal de Vitória da Conquista possui dois Círculos Escolares Intermediários na área rural, com 42 unidades escolares e uma média de 20 escolas em cada Círculo. Ao todo são 40 professores, 44 funcionários e 1.162 alunos matriculados nessas escolas, com classes do $1^{\circ}$ a $5^{\circ}$ ano do Ensino Fundamental.

Ainda de acordo com as informações relatadas no documento em análise, em 2015 havia uma redução de matrículas dos alunos nas comunidades onde as escolas estão inseridas e, por esse motivo, a secretaria de educação ordenou o fechamento ou "paralisação" de algumas unidades escolares. O termo "escolas paralisadas" está sendo usado no documento analisado para indicar o fechamento das escolas que tiveram redução de alunos, garantido para estes o atendimento do transporte escolar para o seu deslocamento às escolas próximas na mesma região. Visando regulamentar a garantia de 
uma política educacional efetiva para os povos do campo no município estudado, o FOMEC destacou no Art. $5^{\circ}$ da proposta de resolução elaborada pelos seus integrantes os seguintes aspectos.

Art. $5^{\circ}$ - A Educação do Campo do Sistema Municipal de Ensino de Vitória da Conquista deve respeitar os seguintes princípios: I - compreender o trabalho como princípio educativo e a cultura como matriz do conhecimento; II - respeitar a diversidade da população do campo em todos os seus aspectos; III - definir projetos educativos com pedagogias e tecnologias condizentes às condições e aos anseios e demandas das populações do campo; IV - reconhecer os espaços escolares como espaços públicos de ensino e aprendizagem, produção de conhecimento e articulação de experiências de vida dos educandos; V desenvolver políticas de formação de profissionais da educação para o atendimento às especificidades educacionais do município, conforme as localidades rurais, considerando as condições concretas da produção e reprodução social da vida no campo; $\mathrm{VI}$ - valorizar a identidade da escola por meio de projetos político-pedagógicos específicos da cada unidade de ensino com organização curricular e metodológica adequadas às necessidades dos educandos e comunidades através de parcerias com os Sindicatos e Movimentos Sociais do Campo; VII - flexibilizar a organização do ensino, visando à adequação do tempo pedagógico, à definição, dos processos de organização das turmas, sem prejuízos das normas de proteção à infância contra o trabalho infantil; VIII adequar o calendário letivo respeitando às diferenças de cada localidade, conforme as condições climáticas do meio rural; VIII - manter controle de qualidade da educação escolar, com a participação efetiva da comunidade e dos movimentos sociais relacionados às questões do campo, na gestão da escola (FOMEC, 2017, p. 2-3) $)^{3}$.

Outra ação administrativa do município que vem interferindo de forma positiva na locomoção dos profissionais de educação e dos alunos da rede de ensino é a política do transporte escolar. Esse processo de deslocamento realizado tanto na zona urbana quanto na rural, apesar da sua positividade, também tem apresentando algumas contradições durante a garantia deste direito social dos estudantes e professores, pois são vistos de forma diferenciada pelos prestadores de serviços sobre o uso do transporte na zona rural do município quando estes não aceitam disponibilizar os veículos com qualidade para realização deste deslocamento. São poucos os prestadores que apresentam veículos com boa qualidade para prestar serviço no meio rural. Geralmente, os donos do transporte contratado apresentam um veículo com excelentes condições na vistoria e disponibilizam outro quando tem início a prestação de serviço. Esta troca de veículos tem trazido muitos problemas na relação entre os professores e os responsáveis pelo setor de transporte. (SANTOS; CARDOSO; OLIVEIRA, 2017).

\footnotetext{
${ }^{3}$ Para consultar a proposta de Resolução do Fomec, sugerimos a consulta à dissertação de Luciene Rocha Silva (2017, p. 150-155), publicada no site da UESC, em: http://www.biblioteca.uesc.br/biblioteca/bdtd/201520088D.pdf
} 
Em Vitória da Conquista, a política de transporte para professores e alunos teve início com a implementação do Fundo de Desenvolvimento do Ensino Fundamental (FUNDEF), Emenda Constitucional de $n^{\circ}$ 014/97, que permite aos estados e municípios, por meio de complementariedade de verbas da União e manutenção do Ensino Fundamental, garantir recursos para pagamento de salários e manutenção das escolas. Até 1996, um pequeno número de professores recebia passagens para o seu deslocamento profissional no referido município, o que acontecia apenas para os docentes que trabalhavam em algumas regiões mais distantes que tinham linhas de transporte de passageiros intermunicipal asseguradas pelas empresas locais. Geralmente estas passagens eram adquiridas pelo poder público municipal das empresas Novo Horizonte e Viação Suburbana, únicas empresas de ônibus coletivo que monopolizavam há quase 30 anos o transporte coletivo na cidade, que trafegavam pelos bairros da zona urbana e para alguns distritos da zona rural, como Inhobim, José Gonçalves, Bate Pé e Iguá4. Até aquele momento os professores lotados nas escolas rurais não tinham transporte assegurado pelo gestor municipal. Geralmente usavam a "carona" para garantir o seu deslocamento para o trabalho. Os atrasos na chegada à escola, os assédios sexuais, a ausência de aulas eram constantes problemas existentes devido à falta do transporte escolar. Com a mudança do governo municipal em 1997, o transporte do professor passou a ser assegurado, o que amenizou a grave situação das condições de trabalho dos professores municipais. (SIMMP,1998).

Para atender às necessidades de locomoção de alunos e professores e a manutenção das escolas, o município contou em 2016 com uma frota de 220 veículos, distribuídos em ônibus, micro-ônibus, vans, carros-pipas, automóveis Kombi, caminhão baú. A frota terceirizada totalizava, à época, 220 veículos dos quais 179 eram destinados ao transporte de alunos e 42 para o transporte de professores. Segundo relatório emitido pelo setor de transporte da Secretaria de Educação, a frota própria do município é composta de 19 ônibus, 7 micro ônibus, 15 Kombi, 3 Fiat Uno, 2 Fiat Doblô, 1 Fiat Estrada, 1 Fiat Courier e 3 caminhões. A equipe de transporte é formada por um coordenador geral, centrado no setor de transporte da SMED, e três funcionários auxiliares, 37 condutores, sendo a maioria deles efetivos e apenas dois com regime de contrato, além de 12 monitores para atendimento de alunos com necessidades especiais e da educação infantil. Ao todo são 409 roteiros distribuídos nos turnos matutino,

\footnotetext{
${ }^{4}$ Informações extraídas de uma cópia de ata de reunião realizada pelo Sindicato do Magistério Municipal Público de Vitória da Conquista data de 15/05/1998. (SIMMP/VC,1998).
} 
As Políticas Municipais de Educação do/no campo em Vitória Da Conquista- Bahia: um diálogo sobre a interrelação com a

vespertino e noturno. Segundo informações do setor de transporte da SMED, a frota própria perfaz em média 300 mil quilômetros mensais e a frota contratada, 500 mil quilômetros no mesmo período. $\mathrm{O}$ atendimento ao transporte escolar para as escolas nucleadas é menor, isto porque em sua totalidade o setor atende apenas a 26 das 47 escolas.

Quanto aos recursos financeiros, o relatório informa que foram investidos pelo município, até novembro de 2016 , uma quantia de $R \$ 4.890,105,41$ para o transporte com alunos e $R \$ 1.148,027,27$ com transporte de professores, totalizando um valor de $R \$$ $6.038,132,68$. Em 2015. Os gastos com transportes foram superiores, chegando à fração dos $\mathrm{R} \$ 9$ milhões investidos no transporte de alunos e professores ${ }^{5}$. A redução, provavelmente, deve-se ao fechamento das escolas que vem ocorrendo no munícipio e, consequentemente, ao processo de nucleação das unidades de ensino que funcionam como classes multisseriadas, localizadas em regiões distantes e de difícil acesso no meio rural.

Verifica-se, portanto, segundo dados estatísticos apresentados, que o município atende em parte à legislação que normatiza a Educação do Campo com relação ao transporte escolar e às Diretrizes operacionais, conforme exposto no Decreto 7.352/2010, em seu Artigo $4^{\circ}$, Inciso IX, quando se trata da "oferta de transporte escolar, respeitando as especificidades geográficas, culturais e sociais bem como os limites da idade e etapas escolares" (BRASIL, 2010, p. 03). Ainda há uma necessidade de o município adequar-se para o atendimento à Educação Infantil no meio rural. Atualmente, existe apenas uma creche e pouquíssimas escolas dão atendimento à infância no meio rural. Dentre as localidades atendidas, apenas o Distrito de Iguá, localizado a $22 \mathrm{~km}$ de distância da cidade, possui instalação própria que oferece condições à educação infantil.

Essa é a realidade do campo em Vitória da Conquista. Sempre que as políticas públicas se aproximam da comunidade rural, nunca chegam de forma legítima como idealizadas. As condições para o seu oferecimento ainda são desfavoráveis e precárias, conforme os dados evidenciaram. A política do monopólio, do assistencialismo, ainda é receptiva aos legítimos representantes do povo, mesmo os considerados progressistas. $\mathrm{O}$ homem do campo ainda é muito carente de políticas públicas e sociais, como por exemplo a de transporte, tanto para o atendimento individual como escolar, de pavimentação das estradas para melhorar o acesso, de horários de transporte disponíveis e acessíveis à

\footnotetext{
${ }^{5}$ Informações extraídas de relatórios emitido pelo setor de transporte da Secretaria Municipal de Educação referente ao ano 2015/2016. (SMED, 2016).
} 
população, além de outras necessidades reais e urgentes. Observamos que muitas localidades rurais ainda não estão sendo atendidas pelo transporte escolar da forma como prevista em lei neste município, sendo paralisadas ou fechadas, como informa o relatório, visando reduzir gastos, sem que o município se preocupe com a situação de comodidade dos alunos e com a cultura específica presente no cotidiano do homem do campo, desrespeitando sua identidade. Para tentar regulamentar os problemas de infraestrutura detectados na pesquisa-ação, o FOMEC destacou no Artigo $6^{\circ}$ da proposta de Resolução elaborada os seguintes aspectos.

Art. $6^{\circ}$ - A oferta da Educação do Campo no Município deve assegurar; I - criação e reabertura de escolas, restruturação das existentes, que foram paralisadas no campo, prioritariamente para a oferta da Educação Infantil; II - condições de infraestrutura, atendendo os critérios de sustentabilidade socioambiental e bem estar estabelecidos nas normas vigentes, incluindo ainda as áreas de lazer, desportos e atividades culturais adequadas aos processos pedagógicos; III produção de materiais didáticos e livros que dialoguem com o contexto local; IV equipamentos, laboratórios de informática, salas multifuncionais, bibliotecas e/ou salas de leituras e brinquedotecas, previsto nos respectivos projetos educativos; V- alimentação escolar de qualidade com cardápio adequado a cultura da comunidade local, respeitando as exigências das normas nacionais de Segurança Alimentar; VI - selecionar professores do quadro efetivo ou temporário com perfil, qualificação e experiências comprovadas para atuar nas escolas do campo; VII garantir a gestão democrática, por meio de eleição direta para os gestores dos Círculos Escolares e Escolas Nucleadas Rurais, de seleção para os coordenadores pedagógicos, bem como o fortalecimento e autonomia para os conselhos escolares e/ou colegiados, mediante a sua participação na tomada de decisão política, administrativa e pedagógica da escola; VIII - garantir transporte escolar de qualidade para alunos e professores, observando as normas de segurança para deslocamento, adequando às condições locais e priorizando o intracampo; IX - elaborar um currículo adequado à realidade do campo, respeitando a cultura, os saberes, as formas de trabalho, o meio ambiente dos sujeitos camponeses que vivem e convivem no campo (FOMEC, 2017, p. 3).

Muitas lutas e resistência ainda precisam ser realizadas por parte dos movimentos sociais do campo visando amenizar as contradições presentes nesta realidade social para assegurar vida digna no meio rural por meio das políticas públicas.

\section{BREVES CONSIDERAÇÕES}

O panorama histórico que nos atraiu para o campo da pesquisa com a intenção de aprofundar o olhar para as produções já existentes a respeito do conhecimento e da legislação que orientam a Educação do Campo no país também nos levou para a busca de um novo conhecimento, por meio de uma investigação sobre a Política Municipal de Educação do Campo em Vitória da Conquista - Bahia, no período de 2010 a 2017, com o 
As Políticas Municipais de Educação do/no campo em Vitória Da Conquista- Bahia: um diálogo sobre a interrelação com a

objetivo de analisar se as ações estruturantes administrativas e pedagógicas implementadas pela Secretaria Municipal de Educação estão em consonância com a política nacional de Educação do Campo, em especial, as Diretrizes Operacionais (2002) que orientam a educação nas escolas do campo no país. Os resultados obtidos, em sua maioria, refletem, a nosso ver, negativamente para a vida das famílias camponesas por não terem a sua identidade cultural vinculada à proposta de ensino levada às escolas do campo, conforme a filosofia de educação que aparece nos estudos realizados.

Ao analisar os documentos, nos deparamos com um currículo escolar inadequado e uma formação continuada dos docentes equivocada, distante da realidade dos camponeses. Encontramos dados que indicam que esses professores pouco conhecem sobre as leis que orientam a educação do campo, bem como sobre as políticas públicas direcionadas para essa realidade. O que nos leva a inferir que o órgão gestor do município ainda não desenvolveu uma política de educação do campo para o meio rural conforme orientam as Diretrizes Operacionais, desrespeitando uma política educacional regulamentada no âmbito Nacional, contradizendo a política do Estado enquanto gerente e regulador das políticas públicas educacionais.

Outra situação que consideramos crítica, observada nos documentos, foi o grande número de fechamento das escolas nucleadas que funcionam com classes multisseriadas e a indiferença com o trato da educação infantil no meio rural, o que consideramos uma perversa política de gestão pública visando à redução de gastos, o que certamente produzirá um grande isolamento social ou a morte de comunidades camponesas, pois quando se fecha uma escola no campo, estrategicamente esse ato político contribui para a expulsão das famílias do campo.

Como aspecto positivo, verificamos que existe uma preocupação para com a política de transporte escolar que assiste a educação municipal em Vitória da Conquista, dispondo de uma frota razoável para atender à locomoção de alunos e professores no meio rural, cujo volume de recursos investidos é considerável, mas ainda com algumas reticências quanto à qualidade dos veículos que prestam o serviço à população rural.

A luta dos movimentos sociais em prol da Educação do Campo deve ser uma constante, o que vem sendo feito pelo FOMEC desde a sua criação no início desta pesquisa. As ações coletivas têm exigido desses sujeitos eterna vigilância na aplicabilidade das políticas na educação pública, conquistadas por meio de intensas mobilizações sociais ao longo de várias décadas, uma vez que não se percebe maior sensibilidade dos governantes em seus programas de governo para com essa parcela da 
As Políticas Municipais de Educação do/no campo em Vitória Da Conquista- Bahia: um diálogo sobre a interrelação com a Política Nacional de Educação do Campo

sociedade que vive no campo e ainda pelo desconhecimento dessas políticas por parte da maioria dos educadores que trabalham com essa realidade de ensino e das comunidades rurais.

Concluímos, afirmando que as políticas públicas para a Educação do Campo são ainda uma área de estudo que precisa ser explorada pelos pesquisadores, cujos resultados devem servir para orientar os gestores, mas também para orientar a luta dos movimentos sociais, uma vez que por meio de diagnósticos estes possam reivindicar os seus direitos com clareza e objetividade. Uma luta que não pode ser fragmentada, individualizada, mas é, sobretudo, coletiva, envolvendo educadores, militantes e os agentes sociais do campo e da cidade. Faz-se necessário que esses elementos nos levem para um intenso processo de mobilização social. Esta consciência de luta é necessária para a libertação dos povos ainda oprimidos.

\section{REFERÊNCIAS}

BRASIL. [Constituição (1988)]. Constituição da República Federativa do Brasil. Diário Oficial da União, n 191-A. Brasília, DF: 05 out. 1988. Senado Federal. Disponível em:

http://www.planalto.gov.br/ccivil 03/constituicao/constituicao.htm. Acesso em: 15 ago. 2020.

BRASIL. Decreto n 7.352 de 04 de novembro de 2010. Dispõe sobre a Política de Educação do Campo e o Programa Nacional de Educação na Reforma Agrária - PRONERA. Diário Oficial da União. Brasília, DF: 05 nov. 2010. Disponível em:

https://www2.camara.leg.br/legin/fed/decret/2010/decreto-7352-4-novembro-2010-609343publicacaooriginal-130614-pe.html. Acesso em: 15 ago. 2020

BRASIL. Lei n 9.394, de 20 de dezembro de 1996. Estabelece as Diretrizes e Bases da Educação Nacional. Diário Oficial da União. Brasília, DF: 23 dez. 1996. Ministério da Educação e Cultura. Disponível em: http://www.planalto.gov.br/ccivil 03/leis/19394.htm. Acesso em: 15 ago. 2020.

BRASIL. Ministério da Educação e Cultura. Educação do Campo: diferenças mudando paradigmas. Cadernos SECAD 2. Brasília, DF: Secretaria de Educação Continuada, Alfabetização e Diversidade, 2007.

BRASIL. Parecer CNE/CEB n 36/2001. Diretrizes Operacionais para Educação Básica nas Escolas do Campo. Diário Oficial da União. Brasília, DF: 13 fev. 2002. Disponível em: http://portal.mec.gov.br/index.php?option=com docman\&view=download\&alias=11989-pceb036-01pdf\&category slug=novembro-2012-pdf\&ltemid=30192. Acesso em: 1 jan. 2020.

CALDART, R. S. Elementos para uma Construção do Projeto Político e Pedagógico da Educação do Campo. In: MOLINA. M. C.; JESUS, S. M. S. A. de (orgs.). Contribuições para a construção de um projeto de Educação do Campo, vol 05, Brasília, DF: Articulação Nacional, 2004. p.24.

CALDART, R.S. Pedagogia do Movimento Sem Terra. Petrópolis: Vozes, 2004a. 
CALDART, R. S. (Org.). Por uma educação do campo: traços de uma identidade em construção. In: Por uma Educação do Campo: identidade e políticas públicas, vol,.4, Brasília, DF: 2002, p 25-36.

ESTEBAN, M. P. S. Pesquisa Qualitativa em Educação: Fundamentos e tradições, Porto Alegre: AMGH, 2010.

FERNANDES, B. M.; MOLINA, M. C. O Campo da Educação do Campo. In: MOLINA, M. C.; JESUS, S. M. A. de. Contribuições Politicas para uma Educação do Campo. Col. Por uma Educação do Campo v. 04 Articulação Nacional, Brasília, DF: 2004. p. 53, 60.

FERNANDES, B. M. Diretrizes de uma caminhada. In: KOLLING E. J.; CERIOLI P. R.; CALDART, R. S (orgs). Educação do Campo: identidade e políticas públicas. Brasília, DF: Articulação Nacional por uma Educação do Campo, 2002. Col. Por uma Educação do Campo, vol. 4.

FONEC - Fórum Nacional de Educação do Campo. Notas para análise do momento atual da Educação do Campo. Seminário Nacional de Educação do Campo. Brasília, 15 a 17 de agosto de 2012.

FOMEC/VC - Fórum Municipal de Educação do Campo de Vitória da Conquista- BA. Ata de Reunião, 16 de abril de 2016. Vitória da Conquista, 2016.

IBGE. Instituto Brasileiro de Geografia e Estatística. Ano 2016. Disponível em: www.cidades.ibge.gov.br. Acesso em: 28 jan. 2017.

KUHN, T. S. A estrutura das revoluções científicas. 9. ed. São Paulo, SP: Perspectiva, 2006.

KOSIK, K. Dialética do Concreto. Tradução: Célia Neves e Alderico Toribic, 2. Ed. Rio de Janeiro: Paz e Terra, 1976.

MACHADO, I. F.; VENDRAMINI, C.R. Políticas Públicas para a Educação do Campo: da necessidade aos limites. Revista Ibero-Americana de Estudos em Educação, v. 8, n. 1, p. 1-16. DOI: https://doi.org/10.21723/riaee.v8i1.6470 Acesso em:18 de agosto de 2020.

MOLINA, M. C.; JESUS. S. M, de A. (Org.). Por uma Educação do campo: contribuições para a construção de um Projeto de Educação do Campo. Col. Por uma Educação do Campo, vol. 5, Articulação Nacional, Brasília, DF: 2004.

MOLINA, M. C.; FREITAS, H. C. de A. Avanços e Desafios na construção da Educação do Campo. Brasília: Em Aberto. v. 24, n.85, p.17-31, abril 2011.

PMVC - Prefeitura Municipal de Vitória da Conquista. Secretaria Municipal de Educação, Coordenação do Transporte Escolar. Relatório de Atividades Período 2015/2016. Vitória da Conquista, BA, 2016.

PMVC - Prefeitura Municipal de Vitória da Conquista. Secretaria Municipal de Educação. Círculo Escolar Intermediário I e II. Relatório de Gestão das Escolas Nucleadas dos Círculos Intermediários I e II, 2014/2015, Vitória da Conquista, BA, 2015.

PMVC - Prefeitura Municipal de Vitória da Conquista. Secretariam Municipal de Educação, Núcleo de Estatística/ Bolsa Família, C.I. NEPBF/SMED N 234/2016 Dados Estatísticos referentes ao Setor Estatístico de Educação do Campo. Datado de 12 de novembro de 2016, Vitória da Conquista, BA, 2016. 
PMVC - Prefeitura Municipal de Vitória da Conquista. Secretaria Municipal de Educação. Apresentação da Secretaria Municipal de Educação. Vitória da Conquista, BA, 2017. Disponível em: www.pmvc.ba.gov.com. Acesso em 17 mar. 2017.

RIBEIRO, M. O Movimento Camponês, Trabalho e Educação - Liberdade Autonomia, Emancipação: princípios/fins da formação humana. 2. Ed. São Paulo: Editora Expressão Popular, 2013.

SACRISTÁN, G. J. Aproximação ao Conceito de Currículo. In: O Currículo: Uma Reflexão Sobre a Prática. Tradução: Ernani F. da Fonseca Rosa, 3. Ed. Porto Alegre: Artmed, 2000. p 13 -34.

SOCORRO, P. E. V.; SANTOS, A. R. dos.; NUNES, C. P. Políticas públicas educativas en Latinoamérica: el contexto brasileño y el venezolano. Educação em Questão (online), v. 55, n. 45, p. 12-41. 2017. Disponível em: https://periodicos.ufrn.br/educacaoemquestao/article/view/12743. Acesso em: 20 fev. 2020.

SANTOS, A. R. dos; CARDOSO, E. A. M.; OLIVEIRA, N. B. Os impactos do PAR nos municípios de Vitória da Conquista, Ilhéus e Itabuna (2013 - 2017). Revista Práxis Educacional, Vitória da Conquista, v. 13, n. 26, p. 110-139, set./dez. 2017. Disponível em:

http://periodicos2.uesb.br/index.php/praxis/article/view/2823/3810. Acesso em: 12 jan. 2020.

SANTOS, A, R. dos. Ocupar, Resistir e Produzir também na Educação! O MST e a Burocracia Estatal: Negação do Consenso, Jundiaí: Paco Editorial, 2013.

SANTOS, A. R. dos. Os movimentos sociais do campo e a reforma agrária do consenso. Curitiba-PR: Editora CRV, 2016.

SANTOS, A.R. dos.; NUNES C. P (Org). Educação e Contextos Diversos: implicações e politicas pedagógicas. Jundiaí: Paco editora, 2017.

SANTOS, A. R.; NUNES, C. P. Reflexões sobre Políticas Públicas Educacionais para o Campo no Contexto brasileiro. Editora, Edufba, Salvador. 2020.

SILVA, L. R. A Política Municipal de Educação do Campo em Vitória da Conquista período 2010 a 2017. 2017, 228 p. Dissertação (Mestrado Profissional em Educação Básica) Universidade Estadual de Santa Cruz, Ilhéus, 2017.

SILVA, J.C. da; MORET, A. de S. A Educação Escolar em assentamentos de hidrelétricas: memórias de um povo esquecido. Debates em Educação | Maceió | Vol. 12 | Número Especial 2. p. 37-59. 2020. Disponível em:

https://www.seer.ufal.br/index.php/debateseducacao/article/view/8764/pdf

DOI: 10.28998/2175-6600.2020v12nEsp2p37-59.

SIMMPNC - Sindicato do Magistério Municipal Público de Vitória da Conquista. Ata da Reunião de 15/05/1998. Vitória da Conquista, BA, 1998.

SMED - Secretaria Municipal de Educação. Relatório Ensino Fundamental II - 2015/2016, Núcleo Pedagógico, Vitória da Conquista, BA, 2016.

SMED - Secretaria Municipal de Educação. Relatório das Unidades Escolares zona urbana, zona rural e creches, emitido em 26/02/2020, Vitória da Conquista BA, 2020.

SOARES, É. A. Câmara de Educação Básica, Conselho Nacional de educação, Parecer 036/2001. In: Diretrizes Operacionais para Educação do Campo, Resolução CNE/CEB, DE 03 de abril de 2002. Brasília, DF. 2002. 
As Políticas Municipais de Educação do/no campo em Vitória Da Conquista- Bahia: um diálogo sobre a interrelação com a Política Nacional de Educação do Campo

SOUZA, M. A. de.; MARCOCCIA, P. C. de. Educação do Campo, Escolas Realidades e o Projeto PNE. Revista FAEEB, Educação e Contemporaneidade, Salvador, v. 20, n. 36, p.191-204, jul./dez. 2011, disponível em: https://www.revistas.uneb.br/index.php/faeeba/article/view/310. Acesso em 18 mar. 2017.

SOUZA, M. A. de. Práticas Educativas no Campo. Ponta Grossa: UEPG, 2002.

THIOLLENT, M. Metodologia da pesquisa-ação, Cortez, São Paulo, 2011. 